\title{
A ASSOCIAÇÃO CRISTÃ DE MOÇOS E A PROPAGAÇÃO \\ DOS ESPORTES EM PORTO ALEGRE
}

\author{
Janice Zarpellon Mazo * \\ Carolina Fernandes da Silva ** \\ Tiago Oviedo Frosi ***
}

\begin{abstract}
RESUMO
A fundação da Associação Cristã de Moços (ACM) no princípio do século XX em Porto Alegre, e seu incentivo ao esporte, representa um impulso ao desenvolvimento do campo esportivo na capital do estado do Rio Grande do Sul. Com a instauração da ACM, esportes e costumes dos porto-alegrenses encontraram um espaço fértil de disseminação na sociedade. $O$ presente estudo histórico busca delinear as contribuições da Associação Cristã de Moços na propagação dos esportes em Porto Alegre, nas primeiras décadas do século XX. A realização deste estudo foi viabilizada, principalmente, por meio das seguintes fontes: jornais, revistas, almanaque esportivo e livro comemorativo da ACM Porto Alegre. A representação da ACM em Porto Alegre foi a de grande promotora de cultural corporal a partir de várias práticas esportivas, ao mesmo tempo em que era agente de congraçamento entre grupos, clubes e indivíduos por meio da organização de grandes eventos esportivos.
\end{abstract}

Palavras-chave: Esporte. História. Clube.

\section{INTRODUÇÃO}

A fundação da Associação Cristã de Moços (ACM) no princípio do século XX em Porto Alegre e seu incentivo ao esporte representa um impulso ao desenvolvimento do campo esportivo na capital do estado do Rio Grande do Sul. Neste período, em meio a um gradual processo de modernização, a cidade via surgir práticas esportivas derivadas de outros países inserirem-se em seu cotidiano. Com a instauração da ACM, esportes e costumes dos portoalegrenses encontraram um espaço fértil de disseminação na sociedade.

A ACM iniciou sua atuação na Inglaterra e se alastrou ao redor do mundo. No Brasil, esta associação instalou-se primeiramente na capital do país na época, no Rio de Janeiro, mas não tardou a se expandir para outros Estados. O Rio Grande do Sul foi o segundo Estado a receber o movimento acemista, que se estabeleceu na capital porto Alegre.

\footnotetext{
*Doutora em Ciências do Desporto (FADE/UP). Professora da Escola de Educação Física da UFRGS.

Coordenadora do Núcleo de Estudos em História e Memória do Esporte e da Educação Física (NEHME) da ESEF/UFRGS.

** Doutoranda do Programa de Pós-Graduação em Ciências do Movimento Humano da Escola de Educação Física da Universidade Federal do Rio Grande do Sul. Membro integrante do Núcleo de Estudos em História e Memória do Esporte e da Educação Física (NEHME) da ESEF/UFRGS.

*** Mestrando do Programa de Pós-Graduação em Ciências do Movimento Humano da Escola de Educação Física da Universidade Federal do Rio Grande do Sul. Membro integrante do Núcleo de Estudos em História e Memória do Esporte e da Educação Física (NEHME) da ESEF/UFRGS.
} 
O movimento acemista era sustentado em um tripé de reforma integral do indivíduo, por meio de hábitos morais e intelectuais, além do cultivo da forma física. Nesta perspectiva a ACM trouxe para a capital sul-rio-grandense, novas maneiras de ver e estar na sociedade, bem como a valorização da prática esportiva. Dentre os esportes, destaca-se o voleibol e o basquetebol como contribuição significativa da ACM nas primeiras décadas do século XX.

O presente estudo histórico busca delinear as contribuições da Associação Cristã de Moços na propagação dos esportes em Porto Alegre, nas primeiras décadas do século XX. Este estudo é o desdobramento de um projeto de pesquisa mais amplo intitulado "Esporte e Educação Física no Rio Grande do Sul: estudos históricos", cuja questão norteadora é como se constituiu o campo esportivo no Estado. Considera-se o esporte um fenômeno cultural basilar para a compreensão da formação de uma identidade sul-riograndense e brasileira. Sendo assim, as pesquisas sobre a gênese e desenvolvimento do esporte institucionalizado em associações, sociedades e clubes contribui não apenas para a análise do/no campo esportivo, mas para conhecer a sociedade sul-rio-grandense.

A realização deste estudo foi viabilizada por meio das seguintes fontes consultadas: jornais, revistas, almanaque esportivo, atlas do esporte, banco de dados, sites, livro comemorativo da ACM Porto Alegre, artigo, dissertação e livros. A partir da análise das fontes históricas foram organizados três tópicos que apresentam os resultados da pesquisa. O primeiro intitulado "Young Men Christian Association: da Inglaterra para o Brasil"trata do surgimento da Young Men Christian Association (YMCA) na Inglaterra em meio a Revolução Industrial e a difusão dos seus ideais pelo mundo, chegando ao Brasil. No segundo - A Fundação da Associação Cristã de Moços em Porto Alegre -, abordamos o advento da ACM no Brasil, em particular na cidade de Porto Alegre. E, o terceiro "As Práticas Esportivas da ACM Porto Alegre" registra os esportes e outras práticas corporais difundidas pela ACM na cidade.

\section{Young Men Christian Association: da Inglaterra para o Brasil}

Durante a Revolução Industrial do século XVIII, e juntamente com os vários problemas que acompanharam esta industrialização, foi que eclodiu a Young Men Christian Association na Inglaterra. Paralelamente com os avanços 
tecnológicos que melhoravam a qualidade de vida de uma pequena parcela da população, a grande maioria das pessoas sofria com dificuldades sociais devido ao aumento exacerbado da jornada de trabalho diário. Com o aumento da população nas grandes cidades inglesas, as condições de saneamento e higiene eram precárias (ÁLBUM DO CENTENÁRIO 1901-2001, 2001).

Possivelmente, foi nos apertados dormitórios de trabalhadores da loja Hitchcock andRangers, em Londres, que surgiu a primeira centelha de ideia de fundação da associação. Nesta loja trabalhava George Willians, principal fundador da associação. Ele e outros trabalhadores começaram a ler escritos bíblicos em um "círculo de oração". Acreditava-se que "o objetivo daquele grupo de rapazes foi o de melhorar as condições de vida social e espiritual dos companheiros de profissão" (LOUREIRO, 2006).

O grupo liderado por George Willians, posteriormente, reuniu-se com jovens que realizavam encontros semelhantes em um local distinto e sobre a organização de James Smith. Este dois grupos, no dia seis de junho de 1844, encontraram-se com outros que também compartilhavam das mesmas ideias a fim de organizar uma associação que recebeu o nome de Young Men Christian Association (YMCA). No ano seguinte a fundação, em 1845, a YMCA de Londres já possuía sua própria sede, além de dispor de um local atraente e contar com um secretário profissional, que era encarregado de organizar a sede.

É importante ressaltar que a YMCA foi capaz de reunir jovens de diferentes confissões religiosas em torno do tripé: moral, intelecto e forma física. A associação buscava promover diversos programas, como por exemplo, estudos bíblicos, aulas de línguas estrangeiras, salas de banho e atividades de educação física. A associação é caracterizada como uma instituição educacional, assistencial e filantrópica, sem fins lucrativos, que congrega pessoas sem distinção de raça, posição social, crença religiosa, política ou de qualquer natureza (ÁLBUM DO CENTENÁRIO 1901-2001, 2001, p. 11).

Em 1851 já existiam 16 associações organizadas em diferentes cidades da Inglaterra, Holanda e Escócia. Da Inglaterra, o movimento que congregava basicamente jovens rapidamente se expandiu pela Europa. Após 10 anos de fundação da associação pioneira e a significativa expansão do movimento foi 
realizada a Primeira Conferência Mundial em 22 de agosto de 1855, contando com a participação dos representantes, denominados delegados, da Inglaterra, Escócia, Holanda, Estados Unidos, França, Canadá, Bélgica, Suíça e Alemanha (ÁLBUM DO CENTENÁRIO 1901-2001, 2001).

A expansão do movimento acemista na América Latina iniciou no final do século XIX pela iniciativa do comitê internacional das associações dos Estados Unidos e Canadá. O primeiro país latino a receber uma filial foi o Brasil (OLIVEIRA, 2009). Em 1887, o missionário presbiteriano G.W. Chamberlain, que atuava no Brasil, solicitou ao comitê internacional que fosse enviado um profissional para fundar a primeira ACM no país. Apesar de o movimento acemista ser amplamente difundido pelo mundo, desde a década de 1850, ele só conseguiria ingressar no Brasil após a separação entre o Estado e a Igreja no governo de Ruy Barbosa em 1889 (FROSI, 2006).

Em 1891, depois de quatro anos da escolha do Brasil para sediar a primeira ACM na América Latina, o Secretário Fraternal Myron A. Clark oriundo de Nova lorque chegou a São Paulo para avaliar a viabilidade de fundar a primeira ACM no país(ASSUNÇÂO et al, 2011). Seguiu para conhecer a cidade do Rio de Janeiro e escolheu esta última para sediar a primeira ACM, cuja data de fundação é quatro de julho de 1893. A ACM de São Paulo foi inaugurada somente em 1902 (ACM/SP, 2012), em data posterior a ACM Porto Alegre (ACM/POA, 2012). Durante décadas estas três foram as únicas $A C M s$ no Brasil. Outras ACMs foram fundadas no país, com uma grande distância temporal: Recife em 1907 (Oliveira, 2009); Minas Gerais em 1950 (ACM/MG, 2012); Sorocaba em 1954 (BENITO, 2007); Brasília em 1965; Londrina em 1966 e Itapeva em 1984. A expansão do movimento acemista no Brasil repercutiu na difusão de práticas esportivas, entre outras contribuições nos estados e cidades brasileiras que sediaram a ACM.

\section{A Fundação da Associação Cristã de Moços em Porto Alegre}

No início do século XX, Myron A. Clark visitou Porto Alegre e decidiu pela instalação da ACM na capital do Estado, em 26 de novembro de 1901 (LOUREIRO, 2006; AMARO JÚNIOR, 1942). Em seguida foi realizada a primeira assembleia da conhecida como ACM Porto Alegre e eleita a primeira diretoria para desencadear as ações do movimento acemista. Apesar de 
enfrentar dificuldades nos primeiros anos, em 1904 começou a oferecer os primeiros cursos: português, francês, alemão, aritmética, geografia, história e astronomia. Neste mesmo ano, a ACM de Porto Alegre se filiou a Aliança Brasileira de ACMs composta por Rio de Janeiro e São Paulo, com o intuito de fortalecer o movimento nacionalmente.

As práticas desenvolvidas em Porto Alegre tinham como finalidade promover o desenvolvimento intelectual e moral dos jovens. O desenvolvimento físico também fazia parte da missão do movimento acemista, mas seu incremento será impulsionado pela visita de Frank Long em 1918. Este delegado da ACM dos Estados Unidos acabou permanecendo por longos anos na cidade de Porto Alegre e foi um dos responsáveis pela iniciação a prática do voleibol, do basquetebol e das corridas de rua (ACM, 1991). Além disso, envolveu-se na promoção de competições de natação, pólo aquático e dos chamados na época jogos atléticos que, posteriormente, mudou o nome para Jogos Olímpicos. Frank Long conquistou reconhecimento no campo esportivo, inclusive pelo empreendimento de organizar a Federação Atlética RioGrandense (FARGS) (ACM, 1991, p. 9). Ainda atribui-se ao trabalho dele na ACM, a iniciativa de comemorar o dia das mães, ocorrida pela primeira vez em 1918, não apenas em Porto Alegre, mas no Brasil (ÁLBUM DO CENTENÁRIO 1901-2001, 2001).

Com o passar dos anos, a ACM foi consolidando-se na sociedade portoalegrense e ampliando seus espaços. Em 1923 foi inaugurada a sede social na Rua Vigário José Inácio, no Bairro Centro de Porto Alegre. Dois anos depois, em meados de 1925, o Comendador Maia fez a doação de uma propriedade, localizada na Rua Pantaleão Teles (atual Rua Washington Luis). A construção das instalações no local levou certo tempo, sendo inaugurada em 1934, e permanece até os dias atuais, como sede social da ACM. A nova sede possibilitou que a ACM intensificasse a promoção de práticas esportivas, inclusive algumas já disseminadas pelos clubes porto-alegrenses, como por exemplo, remo, esgrima, tênis, ping-pong e atletismo (ÁLBUM DO CENTENÁRIO 1901-2001, 2001). 


\title{
As Práticas Esportivas da ACM Porto Alegre
}

A ACM valia-se de distintas estratégias direcionadas a formação integral do ser humano, dentre elas os esportes. As práticas esportivas eram utilizadas como um importante instrumento para o desenvolvimento da saúde, de valores morais, espirituais e mentais (MANSKE, 2006). Tendo como alicerce o triângulo eqüilátero - espírito, mente e corpo - assegurava-se a formação dos acemistas.

Inezil Penna Marinho Marinho (1980) refere a função dos esportes e da educação física no movimento acemista:

\begin{abstract}
O objetivo do departamento físico da YMCA é promover por meio de exercícios, recreação e educação, a mais alta eficiência física, mental e moral dos jovens e homens, essencial para 0 melhor desenvolvimento viril do homem cristão. Os objetivos imediatos são a saúde, o controle neuromuscular, o autocontrole emocional, o respeito pelos direitos dos outros, a vida sã e a elevada moral ( $p$. 148).
\end{abstract}

A ACM de Porto Alegre foi uma grande incentivadora do esporte no Rio Grande do Sul. Promoveu práticas corporais e esportivas como o basquetebol, voleibol, corridas rústicas, ginástica, entre outros. De acordo com Amaro Júnior (1942, p. 139) o esporte principal da ACM era o basquetebol, prática inventada na filial dos Estados Unidos. Inclusive foi José Ferreira Amaro Júnior o organizador do primeiro time de basqueteboldo Rio Grande do Sul, na ACM em 1924. Este personagem do universo esportivo era um grande jornalista da cidade de Porto Alegre nas primeiras décadas do século $X X$ e foi um importante incentivador do esporte amador no estado, principalmente 0 basquetebol, seu esporte favorito. Amaro Júnior também foi responsável pela criação dos chamados campeonatos populares, torneios que reuniam associações que não eram registradas nas federações, as quais disputavam competições nos mais variados esportes. Esta iniciativa oportunizara a prática esportiva para muitas de pessoas ao longo dos anos de efetivação, sem contar que era o próprio Amaro Júnior que se encarregava de fazer os regulamentos e elaborar as provas (BRAUNER, 2010).

A grande importância da ACM no basquetebol se faz notar pelos seus resultados expressivos. Em 21 anos de basquete, a equipe acemista se sagrou duas vezes campeã, atrás apenas do Sport Club Internacional com sete títulos, do Porto Alegre com cinco títulos e do São Geraldo com três títulos (AMARO 
JÚNIOR, 1944, p. 43). Na ACM jogaram atletas de destaque como foi o caso de Wilson Santana Vieira, conhecido pelo apelido de Kalunga, que começou a jogar basquete na Praça General Osório, conhecida como Alto da Bronze, depois indo para a ACM. Kalunga era negro e não sofreu barreiras para ingressar na ACM como acontecia em outros clubes de Porto Alegre na época (BRAUNER, 2010).

Outro esporte coletivo foi incentivado pela ACM. O voleibol foi criado pela ACM nos Estados Unidos em 1895 para contemplar aqueles que desejavam praticar um esporte sem contato físico, com movimentos mais lentos e suaves, diferentemente das características do basquetebol. O voleibol chegou ao Rio Grande do Sul no início do século XX, também pela iniciativa da ACM.

Em 1916, uma delegação de atletas da ACM uruguaia veio a Porto Alegre participar de uma competição de atletismo. No período, este esporte ainda era pouco conhecido por este nome. O atletismo era associado a ginástica, por este fato a competição acabou sendo chamada de "Ginástica". Neste evento esportivo, os atletas uruguaios fizeram um jogo exibição de voleibol, que até então era pouco conhecido no Rio Grande do Sul (AMARO JÚNIOR, 1949). Desde então, o voleibol começou a ser mais praticado na ACM e posteriormente, nos anos 1920, a SOGIPA criou um departamento de voleibol.

Juntamente com os esportes tradicionalmente praticados na cidade ganhavam força os esportes anglo-saxônicos. Ao mesmo tempo em que impulsionava a prática do basquetebol e voleibol, a ACM também incentivava o atletismo. Em 1917, sob a coordenação do Secretário Geral da ACM, Frank M. Long foi realizada uma corrida pelas ruas de Porto Alegre, sendo este um dos poucos registros encontrados que marcam o início das corridas de Rua em Porto Alegre (HIDAKA, 2005).

No ano em que encerrou a primeira Guerra Mundial, em 1918, a ACM promoveu uma competição esportiva no antigo campo de futebol do Grêmio Foot-Ball Porto Alegrense, localizado atualmente próximo do Parque Moinhos de Vento. Esta associação teuto-brasileira pela primeira vez cedeu seu espaço físico para que fosse realizada uma competição aberta às outras sociedades esportivas. Contudo, a SOGIPA não foi convidada num primeiro momento para 
a competição. É possível que este incidente tenha ocorrido devido aidentificação da SOGIPA como um clube que congregava teuto-brasileiros e que mantinha estreita relação com a Alemanha. Durante a Primeira Guerra Mundial, a SOGIPA interrompeu temporariamente muitas atividades (MAZO, 2003). Este ato fez com que alguns de seus atletas se inscrevessem por outras associações. Em razão deste ocorrido a ACM fez um movimento forçando o convite a SOGIPA. Após a confirmação de sua participação na competição a SOGIPA submeteu seus atletas a treinamentos intensivos, pois devido a certas circunstâncias estavam aquém aos das demais associações.

A competição iniciou pela manhã com chuva torrencial. A infraestrutura para a realização das provas era precária, Segundo registro não havia poeira, no entanto os pés desapareciam até os tornozelos na areia falsa e molhada, além disso, o clima frio e úmido e a escuridão da noite dificultavam o desempenho dos atletas. Havia alguns obstáculos armados no campo e um monte de serragem descarregada no centro do mesmo indicavam que ali se pretendia realizar as competições que envolvia 104 atletas (AMARO JUNIOR, 1942). Nada estava preparado, as instalações eram primitivas, desde as canchas de salto até o gramado desnivelado, sem contar a terra escorregadia. Ao contrário de outras competições, onde as canchas de corrida e os saltos eram demarcados e determinados, assim como a chegada era provida de aparelhamento próprio, esta, em particular, tinha a fita da chegada segura por dois cavalheiros. Consta que acidentes poderiam ter sido evitados se houvesse espaço limitado para o público, pois o local dispunha de um pavilhão ideal, mas do seu terraço e das suas bancadas não se podiam observar as lutas, já que o público invadira as canchas, envolvendo em massa os competidores. Houve um acidente envolvendo um dos atletas de arremesso de peso, que ao escorregar na terra molhada lançou o peso na direção do público ferindo três pessoas que estavam assistindo a prova, entre os quais, um gravemente (MAZO, 2003). Apesar das condições difíceis, a competição chegou ao fim e a SOGIPA somou mais pontos do que as outras nove associações esportivas porto-alegrenses, tornando-se a campeã da competição (MAZO, 2003).

Esta competição promovida pela ACM, a partir de 1918 foi reeditada anualmente e recebeu o nome de Jogos Olímpicos. As disputas entre as associações porto-alegrenses se desenrolavam durante uma semana, 
envolvendo as mais diversas práticas esportivas, como também os chamados "torneios intelectuais". Ao final dos Jogos era escolhido o Atleta Olímpico (ACM, 1991), considerando o desempenho físico e intelectual, mas também o seu comportamento e a disciplina durante as competições (MANSKE, 2006).

No princípio dos anos 1920, as competições esportivas eram pouco prestigiadas pelos porto-alegrenses como ilustra uma reportagem da Revista do Globo (MAZO, 2004). No torneio realizado em 1922, os pavilhões estavam quase vazios, sem a presença de um público considerável. O secretário da ACM na época, Frank Long, e atletas de outras associações esforçavam-se em várias provas. No entanto seus esforços eram prestigiados por um público quase inexistente.

Apesar da situação crítica Frank Long não desanimou. Em 1922 organizou uma delegação de oito atletas porto-alegrenses, chefiada por Paulo Hecker, que foi participar dos "Jogos Atléticos" realizados no Rio de Janeiro em comemoração ao Centenário da Independência do Brasil (VICARI; MAZO, 2011). Frank Long assumiu o papel de técnico da equipe composta por: Willy Seewald (MAZO; MADURO, 2010), Willy Fick, Oscar Wolf, Emilio Tietzman, Alfredo Doernt, Osvaldo Brueck, Lindolfo Herzog e Álvaro Ferreira de Souza. Estes atletas acabaram por obter excelentes resultados na competição e assim garantiram a participação na equipe brasileira que disputou o Campeonato Latino-Americano de Atletismo (MAZO, 2003).

O empenho de Frank Long e sua equipe e o apoio de algumas associações esportivas contribui para a organização da Liga Atlética Riograndense (LARG), fundada em 1925. Esta Liga reunia a $A C M$ e as seguintes associações esportivas: Grêmio Foot-Ball Porto Alegrense, Clube de Regatas Almirante Barroso, SOGIPA, Clube de Regatas Guaíba, Esporte Clube Eiche e Clube de Regatas Porto Alegre (MAZO, 2010). Os esportes supervisionados pela Liga eram remo, futebol, atletismo, basquetebol, voleibol, entre outros.

O voleibol, após a Segunda Guerra Mundial ganhou maior projeção no mundo, e também no Rio Grande do Sul, principalmente no que diz respeito à adesão das mulheres ao esporte. Até meados da década de 1940, a principal competição de voleibol feminino no Rio Grande do Sul era o campeonato citadino, ano em que passou a se chamar campeonato estadual. Este 
campeonato contava com a participação da $\mathrm{ACM}$, da Sociedade Ginástica Navegantes São João e da SOGIPA (DALSIN, 2006). Fato interessante é que estas equipes competiam com mais de um time, aumentando o número de mulheres nos jogos. No período compreendido entre os anos de 1941 a 1943, a ACM conquistou títulos na categoria masculina, feminino e mista, conforme dados divulgados por Amaro Junior (1943; 1949).

Não apenas no cenário estadual, a ACM Porto Alegre marcou presença nos campeonato de voleibol. Em 1944 foi a única ACM brasileira a ser representada no Campeonato Continental de Voleibol masculino realizado em Montevidéu, Uruguai, no âmbito das comemorações do centenário do movimento acemista no mundo. Segue um trecho da reportagem:

\footnotetext{
Única representante do Brasil, a equipe de volley-ball da ACM de Porto Alegre, empatou em Montevidéu, o certame Sul-Americano, igualando-se com os mais destacados "six" do continente. (...) Embora não tenha sido composta de elementos de primeira grandeza, o "six" da ACM porto-alegrense soube honrar sobremaneira o esporte brasileiro, vencendo três dos jogos em que tomou parte, perdendo uma única partida e derrotando o team do "PillahuincóTribú" tido como absoluto favorito na sua qualidade de campeão de torneios semelhantes há cinco anos (...) (AMARO JúNIOR, 1945, p. 79-80).
}

Curiosamente, o Campeonato Continental de Voleibol terminou empatado entre as equipes do PillahuincóTribú, de Buenos Aires, da ACM de Montevidéu e da ACM de Porto Alegre. Decidiu-se que o torneio final de desempate seria realizado no ano seguinte na ACM de Porto Alegre. Assim aconteceu e em 1946 sagraram-se campeões os representantes da ACM Porto Alegre (AMARO JÚNIOR, 1947, p. 165). Este acontecimento revela que a ACM procurava fazer intercâmbio com outras ACMs da América Latina.

Muitos dos esportes proporcionados pela ACM resultaram da interação com as outras associações. O futebol de salão na época (atual futsal) foi inventado pelo diretor da Seleção da Educação Física Infantil da ACM de Montevidéu, Juan Carlos Ceriani, em 1930, período em que o país estava motivado pela conquista do Campeonato Mundial de Futebol pela seleção uruguaia. Em 1933 foram redigidas e publicadas as primeiras regras do futsal por solicitação do Instituto Técnico Latino Americano da ACM (ÁLBUM DO 
CENTENÁRIO 1901-2001, 2001). Anos depois a ACM Porto Alegre também oferecia futsal.

A cidade de Porto Alegre já cultivava vários esportes, com, por exemplo, natação, remo, futebol de campo, esgrima, atletismo, mas o futsal ainda não tinha sido apresentado (MAZO, 2003). A ginástica, a musculação - pensada como indispensável para um bom condicionamento físico - e o karatê, atividade que ajuda a disciplinar o corpo e a mente foram incorporadas pela ACM mais tardiamente em relação às práticas citadas anteriormente (ACM, 1991, p. 14). O movimento acemista foi responsável pela invenção de alguns esportes e a propagação destas práticas esportivas.

Em particular no Rio Grande do Sul, a ACM Porto Alegre introduziu os esportes nos colégios do Estado, além de ter criado ginásios, praças e centros para a prática esportiva. Além disso, personagens que tiveram atuação destacada em clubes, entidades e instituições de ensino porto-alegrense tiveram a oportunidade de visitar outras ACMs e trazer subsídios para o campo esportivo e à Educação Física em Porto Alegre. Foi o caso de Frederico Guilherme Gaelzer, que na década de 1920 estagiou na matriz da Associação Cristã de Moços dos Estados Unidos, e visitou a ACM de Montevideo no Uruguai. Cabe referir que, provavelmente, Frank Long foi um agente facilitador deste intercâmbio. Com base nessa experiência Gaelzer elaborou programas de lazer como colônias de férias e recreação em parques e praças (CUNHA, 2009).

\section{CONSIDERAÇÕES FINAIS}

O estudo se propôs a registrar a implicação da ACM com a constituição do campo esportivo porto-alegrense. A ACM, nas primeiras décadas do século $X X$ ocupou um espaço de destaque no cenário esportivo. Notamos que a vinda de Frank Long para Porto Alegre significou um incremento das atividades culturais e práticas esportivas.

As ações empregadas por Frank Long conformaram uma posição de poder da ACM em relação a outras associações que ofereciam práticas esportivas. A apresentação do voleibol e basquetebol aos porto-alegrenses, a organização da LARG, o envio de atletas para os Jogos Atléticos no Rio de 
Janeiro e o apoio aos intercâmbios com outras ACMs, são alguns exemplos de ações deste personagem que ocupou encargos nesta instituição, por longos anos. Talvez possamos afirmar que sua liderança marcou uma nova fase esportiva da ACM Porto Alegre.

As competições esportivas e, especialmente, a realização dos Jogos Atléticos em 1918 e sua reedição a partir deste ano com a denominação de Jogos Olímpico são algumas evidências de um novo período não apenas na ACM, mas no campo esportivo porto-alegrense. Tal evento, que envolvia a participação de outras associações, revela a posição ocupada pela ACM e sua aceitação no cenário esportivo da cidade atravessado por associações identificadas culturalmente com distintos grupos sociais. Por outro lado os Jogos podem ser visto como uma competição esportiva, na qual ocorriam lutas simbólicas entre as associações que buscavam asseverar suas representações de identidades culturais por meio do esporte. A vitória da SOGIPA, por exemplo, significou a afirmação de uma sociedade que reunia teuto-brasileiros, com tradição em práticas corporais e esportivas identificadas como sendo "de alemães" ou "de origem" no Estado. Já a força da ACM no voleibol e basquetebol posiciona de forma destacada esta associação nos esportes coletivos. Contudo, quando a SOGIPA incorpora estas práticas esportivas em meados da década de 1920 começa também a rivalizar neste espaço.

Nas competições esportivas, a ACM ganhou destaque, além de promover diversos campeonatos em vários esportes e congregá-los em Jogos Olímpicos anuais. Foram nas disputas de basquetebol e voleibol que a ACM conquistou muito destaque. Desta forma, a representação da ACM em Porto Alegre foi a de grande promotora de cultural corporal a partir de várias práticas esportivas, ao mesmo tempo em que era agente de congraçamento entre grupos, clubes e indivíduos por meio da organização de grandes eventos esportivos.

A ACM surgiu no mundo a partir da Inglaterra, em meados do século XVIII, como uma alternativa de melhora da qualidade de vida do novo perfil de trabalhadores que passaram a existir com a Revolução Industrial. Para tanto, via na reforma integral do indivíduo, onde a moral, o intelectual e a forma física são bases para a estruturação do sujeito social. Rapidamente este movimento abriu filial em várias cidades. Na América Latina, o Brasil foi o primeiro país a 
receber uma filial da ACM, a cidade escolhida foi o Rio de Janeiro, posteriormente, Porto Alegre foi a segunda beneficiada.

A ACM dispunha de grande prestígio no Brasil, pois contribuía com o processo de formação do homem brasileiro. Esta instituição já se preocupava em formar hábitos saudáveis na população por volta da década de 1920. Sem falar da enorme importância que a ACM teve no incentivo a prática de esportes no país.

Da mesma forma, as práticas desenvolvidas em Porto Alegre procuravam tanto de desenvolvimento físico quanto moral dos sujeitos acemistas. Para tanto, a ACM porto-alegrense procurou promover novos esportes, bem como incentivar a prática dos já existentes na cidade. Foi a ACM que introduziu o voleibol, o basquetebol, as corridas de rua e os jogos olímpicos em Porto Alegre.

\section{REFERÊNCIAS}

ACM/MG - ASSOCIAÇÃO CRISTÃ DE MOÇOS. Associação Cristã de Moços. Site da instituição em Minas Gerais. Disponível em: http://www.acmmg.org/historia.html). Acessado em 20/02/2012.

ACM/RS - ASSOCIAÇÃO CRISTÃ DE MOÇOS. Associação Cristã de Moços. Site da instituição em Porto Alegre. Disponível em: http://www.acmrs.com.br/portal/instucional/a-acm. Acessado em 20/02/2012.

ACM/SP - ASSOCIAÇÃO CRISTÃ DE MOÇOS. Associação Cristã de Moços. Site da instituição em São Paula. Disponível em: http://www.acmsaopaulo.org/. Acessado em 20/02/2012.

ÁLBUM DO CENTENÁRIO 1901-2001. Porto Alegre: Associação Cristã de Moços de Porto Alegre, 2001.

ASSOCIAÇÃO CRITÃ DE MOÇOS. ACM 90 Anos. Livro comemorativo. Porto Alegre, 1991. 
ASSUNCÂO, W.; SCHNEIDER, O.; SILVA, A.; OLIVEIRA, A. A Associacão Cristã de Moços e a difusão do americanismo no Brasil (1932-1950). Anais do XI Congresso Espírito-Santense de Educação Física. Vitória. Educação Física nas políticas públicas: trabalho e gestão integrada. Fortaleza: Itarget, 2011, v. 1, p. 1-5.

BENITO, Rosângela.A Influência da Associação Cristã de Moços na Disseminação do Esporte e Lazer em Sorocaba. Dissertação de Mestrado. Programa de Pós-Graduação em Educação Física da Universidade Metodista de Piracicaba. São Paulo, 2007.

BRAUNER, Daniel. A prática do basquetebol na cidade de Porto Alegre: da emergência dos clubes a organização federativa. Dissertação de Mestrado. Escola de Educação Física. Universidade Federal do Rio Grande do Sul. Porto Alegre, 2010.

CUNHA, Maria Luisa. As práticas corporais e esportivas nas praças e parques públicos da cidade de Porto Alegre (1920-1940). Dissertação de mestrado. Escola de Educação Física. Universidade Federal do Rio Grande do Sul. Porto Alegre, 2009.

DALSIN, Karine; GOELLNER, Silvana. O Elegante Esporte da Rede: o protagonismo feminino no Voleibol gaúcho dos Anos 50 e 60. Revista Movimento, v. 12, n. 01, p. 153-171, janeiro/abril de 2006.

FRANCO,Sérgio. Porto Alegre Guia Histórico. $3^{\underline{a}}$ ed. Porto Alegre: Editora da Universidade/UFRGS, 1998.

HIDAKA, Milton; SEGUY, Ari. Associação Cristã de Moços no Brasil - ACM. In DACOSTA, Lamartine (org.). Atlas do Esporte no Brasil. Rio de Janeiro: Editora Shape, 2005.

LOUREIRO, Walk. A Associação Cristã de Moços e suas contribuições ao desenvolvimento da Educação Física e dos Esportes no Brasil. Anais do X 
Congresso Nacional de História do Esporte, Lazer, Educação Física e Dança. Curitiba: UFRP, 2006.

MANSKE, George. Um currículo para a produção de lideranças juvenis na Associação Cristã de Moços de Porto Alegre. Porto Alegre, RS: [s.n.], 2006.

MARINHO, Inezil. História Geral da Educação Física. São Paulo: Cia Brasil Editora, 1980.

MAZO, Janice. A Emergência e a Expansão do Associativismo Desportivo em Porto Alegre (1867-1945): espaço de representação da identidade cultural teuto-brasileira. Tese de Doutorado. Faculdade do Desporto. Universidade do Porto. Portugal, 2003.

MAZO, Janice. Banco de Dados das Associações Esportivas e de Educação Física de PortoAlegre (1867-1945). Novo Hamburgo, RS: Editora da FEEVALE, 2010 (CD ROM).

MAZO, Janice; MADURO, P. A. A trajetória de um atleta olímpico gaúcho: Willy Seewald, o admirável lançador. In REPPOLD, A. R.; PINTO, L. M. M.; Rodrigues, R. P.; ENGELMAN, S. (Org.). Olimpismo e Educação Olímpica no Brasil. Porto Alegre: Editora da UFRGS, 2009, p. 231-240.

MACHADO, W. O glorioso, visita ao Barracão Listrado, onde se abrigam as glórias de um veterano do remo gaúcho: o clube de Regatas "Almirante Barroso". Revista do Globo. Porto Alegre, 1946, n. 424, p. 48-49. In MAZO, Janice. Catálogo do Esporte e da Educação Física na Revista do Globo. CD-ROM. Porto Alegre: PUCRS, 2004.

OLIVEIRA, Paulo. Associação Cristã de Moços: aspectos do esforço civilizador brasileiro na cidade de Recife no final da primeira década do século XX. Anais do XII Simpósio Internacional Processo Civilizador, nov. 2009. 
VICARI, Paulo; MAZO, Janice. Comemorações do Centenário da Independência do Brasil (1922): Jogos Latino-Americanos no Rio de Janeiro e Jogos Olímpicos no Rio Grande do Sul. Anais do XVII Congresso Brasileiro de Ciências do Esporte e IV Congresso Internacional de Ciências do Esporte. Porto Alegre, 2011, v. 1, p. 1-11.

\section{THE YOUNG MEN CHRISTIAN ASSOCIATION AND THE SPREAD OF SPORTS IN PORTO ALEGRE}

\section{ABSTRACT}

The founding of the Young Men Christian Association (YMCA) at the beginning of the 20th century in Porto Alegre, and their encouragement to the sport, represent a stimulus to the development of the sports in the State capital of Rio Grande do Sul, Brazil. With the introduction of the YMCA, sports and customs of the inhabitants of Porto Alegre found a fertile space of dissemination in society. This historical study seeks to outline the contributions of the YMCA in the propagation of sports in Porto Alegre, in the first decades of the $20^{\text {th }}$ century. This study was made possible primarily through the following sources: newspapers, magazines, sports almanac and commemorative book of the YMCA of Porto Alegre. The representation of the YMCA in Porto Alegre was the body cultural promoter through various sports practices, while gatherings agent was among groups, clubs and individuals through the organization of sport events.

Keywords: Sport. History.Club.

\section{CHRISTIAN ASOCIACIÓN YMCA Y LA PROPAGACIÓN DE DEPORTES EN PORTO ALEGRE}

\section{RESUMEM}

La Fundación de la YMCA (ACM) a comienzosdelsiglo XX en Porto Alegre, y el fomento al deporte, representa un estímulo para eldesarrollodel campo de deportes enla capital del Estado de Rio Grande do Sul, Brasil. Conlaintroducción de la ACM, deportes y costumbres de los porto-alegrenses encontraronunespacio fértil de difusiónenlasociedad. Este estudio histórico pretende delinear lasaportaciones de la YMCA enlapropagación de los deportes en Porto Alegre, enlasprimeras décadas delsiglo XX. Este estudiofueposible principalmente a través de lassiguientesfuentes: periódicos, revistas, deportes Almanaque y libro conmemorativo de la ACM de Porto Alegre. La representación de la ACM en Porto Alegre fueel promotor cultural mayordelcuerpo de diversas prácticasdeportivas, mientras que fue agente de reuniones entre grupos, clubes y personas a través de laorganización de grandes eventos deportivos.

Palabras clave: Deporte. Historia. Club. 